Research Paper:

\title{
Prevalence of Anesthesia Complications in Orthopedic Surgeries and Its Related Factors
}

\author{
Hossein Kiani ${ }^{1}$ (D), Masoumeh Hoseinian ${ }^{1}$ (D), Zohreh Sadat ${ }^{1}$ (D), Neda Mirbagher Ajorpaz ${ }^{2 *}$ (iD) \\ 1. Department of Nursing and Midwifery, Trauma Nursing Research Center, Faculty of Nursing and Midwifery, Kashan University of Medical Sciences, \\ Kashan, Iran. \\ 2. Department of Nursing and Midwifery, Autoimmune Diseases Research Center, Faculty of Nursing and Midwifery, Kashan University of Medical \\ Sciences, Kashan, Iran.
}

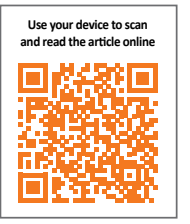

Citation: Kiani, H., et al., 2021. Prevalence of Anesthesia Complications in Orthopedic Surgeries and Its Related Factors. Journal of Client-Centered Nursing Care, 7(2), pp. 123-130. https://doi.org/10.32598/JCCNC.7.2.295.3

doifinttps://doi.org/10.32598/JCCNC.7.2.295.3

\section{(i) (3)}

Article info:

Received: 24 Dec 2020

Accepted: 16 Mar 2021

Published: 01 May 2021

\section{A B S T RA C T}

Background: The duration of surgery in orthopedic surgeries is often longer than one hour. Therefore, these patients are at further risk of complications induced by general anesthesia. The present study aimed to determine the prevalence of anesthesia complications in orthopedic surgeries and its related factors.

Methods: This cross-sectional study was performed on 400 patients undergoing orthopedic surgery in Shahid Beheshti Hospital of Kashan Province, Iran, in 2020. The study subjects were recruited by convenience sampling and included those who underwent general anesthesia for elective surgery and were transferred to Post-Anesthesia Care Unit (PACU). The research instruments included a demographic questionnaire and a checklist for recording complications (shivering, pain, nausea, vomiting, \& vital signs). The necessary data were recorded after the patient was admitted to the PACU, as well as half an hour and one hour later. The obtained data were analyzed using the Chi-squared test, Independent Samples t-test, one-way Analysis of Variance (ANOVA), Pearson correlation coefficient, and logistic regression analysis in SPSS 16.

Results: The present research results suggested that the most and least frequent complications were vomiting $(91.8 \%)$ and changes in blood pressure $(5 \%)$, respectively. Gender was significantly associated with pain, nausea, and hypertension $(\mathrm{P}<0.05)$. The Pearson correlation coefficient data indicated a significant relationship between the duration of anesthesia and the mean scores of shivering, pain, nausea, tachycardia, and tachypnea $(\mathrm{P}<0.05)$. There was also a significant relationship between the types of surgery and shivering, pain, blood pressure, and nausea $(\mathrm{P}<0.05)$. Pulse rate was significantly associated with complete intravenous anesthesia and the duration of anesthesia $(\mathrm{P}<0.05)$.

Conclusion: The relatively high incidence of post-anesthesia complications in orthopedic surgeries indicates the significance of employing skilled personnel as well as using adequate monitoring equipment at the PACU. Such measures help to decrease mortality and morbidity among patients, also save on hospital costs.

Orthopedic surgeries

Shivering, Postoperative

nausea, Vomiting

*Corresponding Author:

Neda Mirbagher Ajorpaz, PhD.

Address: Department of Nursing and Midwifery, Autoimmune Diseases Research Center, Faculty of Nursing and Midwifery, Kashan University of Medical Sciences, Kashan, Iran.

Tel: +98 (913) 2130397

E-mail: mirbagher_n@kaums.ac.ir 


\section{Highlights}

- Vomiting was the most frequent complication after anesthesia in orthopedic surgeries.

- There was a significant relationship between the duration of anesthesia and the mean scores of shivering, pain, nausea, tachycardia, and tachypnea.

- Tachycardia was significantly associated with complete intravenous anesthesia and the duration of anesthesia.

\section{Plain Language Summary}

The duration of surgery in orthopedic surgeries is often longer than one hour. Therefore, these patients are at higher risks of complications from general anesthesia. The present study determined the prevalence of post-anesthesia complications in orthopedic surgeries and its related factors in 2020. The obtained results indicated that the most complication after anesthesia in orthopedic surgeries was vomiting; the least complication was changes in blood pressure. Gender was significantly associated with pain, nausea, and hypertension. There was a significant relationship between the duration of anesthesia and shivering, pain, nausea, and pulse rate. There was also a significant relationship between the types of surgery and shivering, pain, blood pressure, and nausea. Pulse rate was significantly associated with complete intravenous anesthesia and the duration of anesthesia.

\section{Introduction}

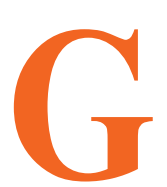

eneral anesthesia is usually used in numerous surgeries that last for more than an hour. Anesthesia and surgery impose extensive stress on the patient (Miller et al. 2015). The body's response to stress and surgical injury includes the secretion of cortisol, catecholamine, cytokines, and glucagon. The body's response to surgery causes an imbalance of essential physiological functions. Concurrently, the delayed effect of anesthetics and muscle relaxants undermines the body's natural ability to re-establish physiological balance and maintain health (Kellner et al. 2018); subsequently, this condition leads to post-anesthesia complications in the Post-Anesthesia Care Unit (PACU). About one-third of patients admitted to the recovery room develop at least one complication after anesthesia (Miller et al. 2015; Barney, Fuller \& Habib 2020). Studies also suggested that surgery and anesthesia can trigger stressors (hormonal \& inflammatory) that increase the risk of complications (Fouladpour et al. 2016; Elsharydah et al. 2020). The prevalence of orthopedic surgeries in Iran is high due to the high frequency of road accidents, weight gain, poor nutrition, the prevalence of osteoporosis, and not using protective equipment by the elderly (Abbasi \& Ahmadi 2013). General anesthesia generates higher complications than spinal anesthesia; it is commonly used for long-term operations, like orthopedic surgeries (Kellner et al. 2018).
Patients undergoing orthopedic surgeries (total hip replacement, hemiarthroplasty, limb fractures, \& intramedullary nails) usually undergo long-term surgeries (Bause, 2018). Furthermore, the prevalence of anesthesia complications after orthopedic surgery is higher than that of other types of surgeries (Bause 2018; Kellner et al., 2018). Nausea, vomiting, hypoxia, hypothermia, shivering, and cardiovascular instability have been reported as common postoperative complications in orthopedic surgeries (Kayalha, Roushanfekr \& Ahmadi 2014). The American Anesthesia Association has introduced characteristics, such as prolonged anesthesia, emergency surgery, a history of underlying disease, and smoking as the causes of postoperative anesthesia complications (Finsterwald et al. 2018). Increasing the duration of the administration of the inhaled anesthetics is associated with the incidence of postoperative shivering after surgery (Poveda \& Nascimento 2017; Mendonça et al. 2019). Kellner et al. (2018) revealed that $48 \%$ of patients had experienced complications after surgery and anesthesia. The most common complications included respiratory problems, hypotension, bradycardia and tachycardia, neurological problems, and delirium, as well as delayed awakening, respectively. In their study, the factors that generated the greatest impact on the incidence of complications included the duration of anesthesia between 2-4 hours, emergency surgery, and the type of surgery. The related results also signified that abdominal and orthopedic surgeries presented the highest rates of complications (Kellner et al. 2018). 
The shorter the duration of surgery in colorectal cancer surgery, the less the postoperative delirium (Zhou \& Wang 2018). However, some studies indicated no significant relationship between the type of anesthesia, the type of surgery, the duration of surgery, and postanesthesia complications (Son et al. 2016). Brady et al. (2018), found no significant relationship between the duration of anesthesia and the type of anesthesia, and the type of surgery, pain, shivering, and medications used during anesthesia. The authors suggested further research in this field (Brady et al. 2018). Considering the high prevalence of orthopedic surgery and the relatively high incidence of complications after anesthesia, the present study aimed to determine the prevalence of anesthesia complications and their related factors in orthopedic surgeries.

\section{Materials and Methods}

This was a descriptive and cross-sectional study. The study population consisted of patients who underwent orthopedic surgery in the operating rooms of Beheshti Hospital in Kashan Province, Iran, from January 2020 to September 2020 and met the inclusion criteria. The following formula was used to calculate the required sample size. In this formula, the frequency of the anesthesia complications was considered to be $50 \%$. Therefore, considering $\mathrm{d}=0.05, \mathrm{P}=0.50$, and $\mathrm{q}=1$, a sample size of 385 was obtained; however, 400 subjects were recruited for further accuracy (Formula 1).

$$
\text { 1. } n=\frac{z^{2}{ }_{1-\frac{a}{2}} \sigma^{2}}{d^{2}}
$$

The inclusion criteria of this study were patients undergoing orthopedic surgery (total hip replacement, hemiarthroplasty, limb fractures, intramedullary nail); an age range of 18-60 years; no systemic diseases (cardiovascular, respiratory, diabetes); no dependence on narcotics or psychotropic drugs, and willingness to participate in the study. The exclusion criteria were the emergency orthopedic surgeries (e.g. rib fractures embedded in the lungs, fractures with intra-abdominal bleeding, \& ruptured viscera), and a surgery duration of $>3$ hours. The study subjects were selected by convenience sampling technique. All the subjects voluntarily participated in the study and completed the informed consent form before undergoing surgery.

The study tools included a sociodemographic questionnaire (age, gender, smoking, educational level, the type of surgery, the time of surgery, the duration of anesthesia, the method of anesthesia, \& surgeons' experiences) and a checklist for recording the complications (shiver- ing, pain, nausea, vomiting, \& vital signs). The necessary data were recorded after admitting the patient to the PACU as well as half an hour and an hour later. The study subjects' demographic information was recorded after the surgery. All necessary data were recorded by the first researcher. Shivering was measured by a shivering assessment questionnaire in the PACU. The scoring of this questionnaire was as follow: no shivering (0); mild shivering: mild contractions in the muscles of the face and neck (1); moderate shivering: obvious shivering in the neck, shoulders, and extremities (2); severe shivering: obvious shivering throughout the body (3) (Nasiri et al. 2015; Ma et al. 2017). This tool presented interrater reliability of $81 \%-86 \%$ (Badjatia et al. 2008). In the present study, its inter-rater reliability was established by the researcher and the recovery nurse on 20 patients and measured as $83 \%$.

Nausea and pain were measured by the Wong-Baker Faces Pain Rating Scale. This scale consists of a card with faces (from laughter to crying). Faces illustrate the severity of pain and include face zero: completely happy and without any pain, face 2 : less pain, face 4 : a little more pain, face 6 : much more pain, face 8 : too much pain, and face 10: the most severe pain. This scale also has been used to measure episodes of fatigue and nausea in semi-conscious patients (Garra et al. 2013). The validity and reliability of this scale were calculated by the content validity method and Cronbach's alpha coefficient (0.95) (Garra et al., 2013). In the present study, the Cronbach's alpha coefficient of this tool was calculated to be 0.89 . Vomiting was measured by the frequency of vomits and the temperature was calculated by a mercury thermometer in the axillary area. Pulse rate, blood pressure, and respiration rate were recorded according to a monitor connected to the patient by the recovery nurse and the first researcher.

General anesthesia protocol was performed for all study patients based on the anesthesia protocol introduced by Miller (Miller et al. 2015). During surgeries, the operating room temperature was set at $21^{\circ} \mathrm{C}$. After surgery, the patient was delivered to the PACU. At the time of admission to the recovery room, the patients underwent cardiac monitoring by a recovery nurse. Then, the complications of anesthesia, including shivering, pain, nausea, vomiting, and vital signs (pulse \& blood pressure, respiration, temperature) were measured and recorded by the first researcher or recovery nurse at the time of admission to recovery, as well as half an hour, and one hour later. 
The obtained data were analyzed in SPSS 16. The Chisquared test was used to examine associations between the categorical data. Pearson correlation coefficient and logistic regression analysis were also used to determine the relationship between the study variables. A significance level of 0.05 was considered for all statistical analyses.

\section{Results}

The Mean \pm SD age of the patients was $37.12 \pm 14.12$ years. Most patients were female $(79.8 \%)$ with a diploma $(48.3 \%)$. Furthermore, the most common types of surgery and anesthesia were limb fractures (48.8\%) and complete venous anesthesia (52.3\%), respectively (Table 1).
Gender (female) was significantly associated with pain, nausea, and hypertension $(\mathrm{P}<0.05)$. The Pearson correlation coefficient results indicated a significant relationship between the duration of anesthesia and the mean scores of shivering, pain, nausea, tachycardia, and tachypnea $(\mathrm{P}<0.05)$. Moreover, one-way ANOVA data revealed a significant relationship between the types of surgery and shivering, pain, hypertension, and nausea $(\mathrm{P}<0.05)$. There was a significant relationship between complete intravenous anesthesia and the duration of anesthesia and tachycardia $(\mathrm{P}<0.05)$ (Table 2$)$.

The present study findings indicated that the most frequent complication after anesthesia was vomiting (91.8\%); the least complication was changes in blood

Table 1. The demographic and clinical characteristics of the study participants $(n=400)$

\begin{tabular}{|c|c|c|}
\hline \multicolumn{2}{|c|}{ Variable } & Mean \pm SD/No. (\%) \\
\hline \multicolumn{2}{|c|}{ Age (year) } & $37.12 \pm 14.12$ \\
\hline \multicolumn{2}{|c|}{ The duration of anesthesia (minute) } & $136.37 \pm 1.32$ \\
\hline \multicolumn{2}{|c|}{ Surgeon's experience (year) } & $3.2 \pm 1.08$ \\
\hline \multirow{2}{*}{ Gender } & Female & 319 (79.8) \\
\hline & Male & $81(20.3)$ \\
\hline \multirow{3}{*}{ Educational level } & Under diploma & $73(18.3)$ \\
\hline & Diploma & $193(48.8)$ \\
\hline & Above diploma & $134(33.5)$ \\
\hline \multirow{4}{*}{ The type of surgery } & Total hip replacement & $50(12.5)$ \\
\hline & Hemiarthroplasty & 72 (18) \\
\hline & Limb fracture & $195(48.8)$ \\
\hline & Intra-medullary nail & $83(20.8)$ \\
\hline \multirow{4}{*}{ Surgery time } & Morning & $184(46)$ \\
\hline & Afternoon & 77 (19.3) \\
\hline & Evening & $74(18.5)$ \\
\hline & Night & $65(16.3)$ \\
\hline \multirow{3}{*}{ Anesthesia method } & Inhalation anesthesia & $50(12.5)$ \\
\hline & Balanced anesthesia & $141(35.3)$ \\
\hline & Complete venous anesthesia & $209(52.3)$ \\
\hline \multirow{2}{*}{ Smoking } & Yes & $163(40.8)$ \\
\hline & No & 237 (59.3) \\
\hline
\end{tabular}


Table 2. The relationship between the complications of surgery and the study participants' demographic and clinical data

\begin{tabular}{|c|c|c|c|c|c|c|c|c|}
\hline Variable & Shivering & Pain & Nausea & Vomiting & Tachycardia & Hypertension & Tachypnea & Test \\
\hline Age & $\begin{array}{l}r=0.11 \\
P=0.90\end{array}$ & $\begin{array}{c}r=0.24 \\
P=0.0001\end{array}$ & $\begin{array}{l}r=0.43 \\
P=0.40\end{array}$ & $\begin{array}{l}r=0.87 \\
P=0.06\end{array}$ & $\begin{array}{l}r=0.57 \\
P=0.11\end{array}$ & $\begin{array}{l}r=-0.21 \\
P=0.01\end{array}$ & $\begin{array}{l}r=0.32 \\
P=0.10\end{array}$ & $\begin{array}{c}\text { Pearson correla- } \\
\text { tion coefficient }\end{array}$ \\
\hline $\begin{array}{c}\text { Male } \\
\text { Female }\end{array}$ & $P=0.11$ & $P=0.005^{*}$ & $P=0.44$ & $P=0.56$ & $P=0.25$ & $P=0.26$ & $p=0.76$ & $\begin{array}{l}\text { One-way } \\
\text { ANOVA }\end{array}$ \\
\hline Educational level & $P=0.11$ & $\mathrm{P}=0.01^{*}$ & $P=0.96$ & $P=0.17$ & $P=0.23$ & $P=0.0001^{*}$ & $P=0.91$ & $\begin{array}{l}\text { One-way } \\
\text { ANOVA }\end{array}$ \\
\hline $\begin{array}{l}\text { Duration of anes- } \\
\text { thesia }\end{array}$ & $\begin{array}{l}r=0.35 \\
P=0.01^{*}\end{array}$ & $\begin{array}{c}r=0.41 \\
P=0.005^{*}\end{array}$ & $\begin{array}{c}r=0.30 \\
P=0.002^{*}\end{array}$ & $\begin{array}{l}r=0.89 \\
P=0.74\end{array}$ & $\begin{array}{l}r=0.24 \\
P=0.04^{*}\end{array}$ & $\begin{array}{l}r=0.88 \\
P=0.98\end{array}$ & $\begin{array}{l}r=0.29 \\
P=0.01^{*}\end{array}$ & $\begin{array}{l}\text { Pearson correla- } \\
\text { tion coefficient }\end{array}$ \\
\hline $\begin{array}{l}\text { Surgeon experi- } \\
\text { ence }\end{array}$ & $\begin{array}{c}r=-0.76 \\
P=0.97\end{array}$ & $\begin{array}{l}r=0.69 \\
P=0.85\end{array}$ & $\begin{array}{l}r=0.89 \\
P=0.47\end{array}$ & $\begin{array}{l}r=-0.69 \\
P=0.47\end{array}$ & $\begin{array}{l}r=0.60 \\
P=0.80\end{array}$ & $\begin{array}{l}r=0.55 \\
P=0.26\end{array}$ & $\begin{array}{l}r=0.80 \\
P=0.77\end{array}$ & $\begin{array}{l}\text { Pearson correla- } \\
\text { tion coefficient }\end{array}$ \\
\hline Type of surgery & $P=0.0001^{*}$ & $P=0.0001^{*}$ & $P=0.0001^{*}$ & $P=0.50$ & $P=0.19$ & $P=0.008^{*}$ & $P=0.86$ & $\begin{array}{l}\text { One-way } \\
\text { ANOVA }\end{array}$ \\
\hline Surgery time & $\begin{array}{l}r=0.59 \\
P=0.13\end{array}$ & $\begin{array}{l}r=0.40 \\
P=0.80\end{array}$ & $\begin{array}{l}r=0.71 \\
P=0.98\end{array}$ & $\begin{array}{l}r=0.68 \\
P=0.94\end{array}$ & $\begin{array}{l}r=0.66 \\
P=0.37\end{array}$ & $\begin{array}{l}r=-0.90 \\
P=0.85\end{array}$ & $\begin{array}{l}r=0.88 \\
P=0.25\end{array}$ & $\begin{array}{l}\text { Pearson correla- } \\
\text { tion coefficient }\end{array}$ \\
\hline $\begin{array}{l}\text { Anesthesia } \\
\text { method }\end{array}$ & $P=0.007^{*}$ & $P=0.0001^{*}$ & $P=0.001^{*}$ & $P=0.04^{*}$ & $P=0.02^{*}$ & $\mathrm{P}=0.02^{*}$ & $P=0.80$ & $\begin{array}{l}\text { One-way } \\
\text { ANOVA }\end{array}$ \\
\hline Smoking & $P=0.99$ & $P=0.41$ & $P=0.71$ & $P=0.34$ & $P=0.36$ & $P=0.85$ & $\mathrm{P}=0.18$ & $\begin{array}{l}\text { Independent } \\
\text { Samples t-test }\end{array}$ \\
\hline
\end{tabular}

$* \mathrm{P}<0.05$ is significant.

Client- Centered Nursing Care

pressure $(5 \%)$. The most frequent complications were observed after limb fracture surgery $(88 \%)$. Besides, fever was not detected after surgeries in the PACU among the study patients.

The logistic regression analysis data suggested that the type of surgery (hemiarthroplasty) and the time of surgery (evening) presented a positive and significant relationship with shivering $(\beta=0.437, \mathrm{t}=18.19, \mathrm{P}<0.05)$ and pain $(\beta=0.652, \mathrm{t}=38.31, \mathrm{P}<0.05)$. Additionally, nausea was significantly associated with gender, age, and the type of surgery (limb fractures $\&$ intra-medullary nail) ( $\beta=0.777, t=52.08, P<0.05)$. Furthermore, vomiting was significantly and positively associated with the duration of anesthesia and anesthesia method (complete venous anesthesia) $(\beta=-2.40, \mathrm{t}=175.68, \mathrm{P}<0.05)$. Tachycardia was also positively and significantly correlated with the duration of anesthesia, gender, and smoking $(\beta=-3.89$, $\mathrm{t}=118.74, \mathrm{P}<0.05)$.

\section{Discussion}

The present research findings indicated that gender presented a direct relationship with pain, nausea, and hypertension. In the examined women, pain, nausea, and hypertension were more common after surgery, i.e., consistent with the results of the study by Mendonça (2019). There was a direct relationship between the du- ration of anesthesia and the mean scores of shivering, pain, nausea, tachycardia, and tachypnea. As the time of surgery increased, the patient's postoperative shivering, pain, nausea, tachycardia, and tachypnea elevated. Poorsheykhian et al. (2012), and Zhou and Wang (2018) signified a direct relationship between pain intensity, gender (male), and the duration of surgery. As the duration of surgery increased, the patient's postoperative pain enhanced (Poorsheykhian et al. 2012; Zhou, Wang 2018). These studies were consistent with the results of the present study, except for the gender variable. As per Poorsheykhian et al. (2012), complications were higher in males; however, in the present study, those were greater in females.

Additionally, there was a direct relationship between the type of surgery and shivering, pain, hypertension, and nausea. These complications were more frequent in limb fracture surgery. The present study data were consistent with those of Boljevic et al. (2019). The results of their study revealed that the type of surgery was associated with postoperative complications. In other words, complications were more prevalent after traumatic fractures (Boljevic et al. 2019). The results suggested that tachycardia is more prevalent in patients with complete intravenous anesthesia and a surgery duration of more than an hour. Misal, Joshi and Shaikh (2016) also demonstrated that patients who received complete intrave- 
nous anesthesia for a long time had further surgical complications, such as tachycardia and pain (Misal, Joshi \& Shaikh 2016).

In the present study, patients' pain after surgery was significantly associated with age, gender, educational level, duration of anesthesia, the type of surgery, and anesthesia method. Another investigation identified a direct relationship between patients' pain after surgery and contextual variables, including age, gender, as well as the type and duration of surgery (Kellner et al. 2018).

In the present study, shivering was associated with the type of surgery, complete intravenous anesthesia, and the increased duration of anesthesia. In another study, there was a significant relationship between the duration of anesthesia and the incidence of shivering after anesthesia (Poorsheykhian et al. 2012). In the Poorsheykhian study, the rate of shivering after surgery was measured as $21 \%$ (Poorsheykhian et al. 2012); in the Entezari study, it equaled 36\% (Entezari-asl et al. 2002), and in another study, it was obtained as 65\% (Buggy \& Crossley 2000). Their studies differed concerning the type of surgery; however, all of these studies revealed that with increasing the duration of surgery, the rate of shivering after anesthesia has also enhanced.

According to the present study data, vomiting was the most common complication after surgery. Also, nausea was significantly higher in female patients with limb fracture surgery, complete intravenous anesthesia, and when the duration of anesthesia was increased. In another study, the incidence of nausea and vomiting was computed as $12 \%$, i.e., more prevalent in females and prolonged surgery cases; however, there was no significant difference between the gender and duration of surgery (Poorsheykhian et al. 2012). The difference between the prevalence of shivering and its related factors in the study of Poorsheykhian and our study could be attributed to the type of surgery. The obtained results were inconsistent with those of Darvishi et al. (2018). Perhaps, this discrepancy is related to the type of anesthesia; as in Darvishi study, only patients who had undergone spinal anesthesia were examined. According to Miller, nausea and vomiting are more prevalent in inhaled anesthesia cases, with a prevalence of 10\%-30\% (Miller et al. 2015). Studies noted that due to the prevalence of nausea and vomiting and the odds of aspiration pneumonia which can be life-threatening, timely prevention and treatment should be given to such cases (Belcher et al. 2017; Mendonça et al., 2019). In the present study, vomiting was the most common complication after surgery. However, in one study, hypertension was reported as the most frequent complication after surgery (Poorsheykhian et al. 2012), i.e., inconsistent with our results. This may be due to the difference in the type of surgery.

The current research results revealed that with increasing the duration of anesthesia, the patient's respiration rate significantly increased. A study determined the incidence of post-anesthesia complications in patients undergoing non-cardiac surgery; accordingly, the relevant results suggested that the rate of tachypnea after anesthesia equaled 51.8\% (Belcher et al. 2017).

\section{Conclusion}

The present study data suggested that the most frequent complication after anesthesia in orthopedic surgeries was vomiting. Gender was significantly associated with pain, nausea, and blood pressure. Furthermore, there was a significant relationship between the duration of anesthesia and the incidence of shivering and nausea, the severity of pain, pulse, and respiratory rate. There was also a significant relationship between complete intravenous anesthesia and the duration of anesthesia, and pulse rate. Therefore, due to the high incidence of complications in orthopedic surgery, recovery room nurses need to be trained in this regard. They should pay great attention to the incidence and control of these complications.

\section{Ethical Considerations}

\section{Compliance with ethical guidelines}

This study was approved by the Ethics Committee of the Kashan University of Medical Sciences (Code: IR.KAUMS.NUHEPM.REC.1399.092). All ethical principles are considered in this article. The participants were informed about the purpose of the research and its implementation stages and provided written informed consent. They were also assured about the confidentiality of their information and were free to leave the study whenever they wished, and if desired, the research results would be available to them.

\section{Funding}

This article was extracted from the MSN thesis of the first author at the Department of Nursing and Midwifery, Faculty of Nursing and Midwifery, Kashan University of Medical Sciences, Kashan. Also Kashan University of Medical Sciences has supported this research. 


\section{Authors' contributions}

Conceptualization: Hossain Kiani, Neda Mirbagher Ajorpaz; Methodology: Masoumeh Hoseinian, Zohreh Sadat; Investigation: Hossain Kiani; Writing the original draft and editing: Neda Mirbagher Ajorpaz, Masoumeh Hoseinian, Zohreh Sadat; Supervision: Neda Mirbagher Ajorpaz.

\section{Conflict of interest}

The authors declared no conflicts of interest.

\section{Acknowledgments}

We would like to thank Kashan University of Medical Sciences for its financial support and all the patients who agreed to participate in the study.

\section{References}

Abbasi, M. \& Ahmadi, A., 2013. [Orthopedic surgery and its resulting liabilities under the Iranian legal system (Persian)]. Medical Law Journal, 7(26), pp. 13-39. http://ijmedicallaw.ir/ article-1-161-en.html

Badjatia, N., et al. 2008. Metabolic impact of shivering during therapeutic temperature modulation: The bedside shivering assessment scale. Stroke, 39(12), pp. 3242-7. [DOI:10.1161/ STROKEAHA.108.523654] [PMID]

Barney, E. Z., Fuller, M. E. \& Habib A. S., 2020. Comparison of metoclopramide and promethazine for the treatment of postoperative nausea and vomiting in the post-anesthesia care unit: A retrospective database analysis. Journal of Clinical Anesthesia, 60, pp. 47-8. [DOI:10.1016/j.jclinane.2019.08.012] [PMID]

Bause, L., 2018. [Complications in orthopedic rheumatologycharacteristics of operative procedures (German)]. Orthopade, 47(11), pp. 949-57. [DOI:10.1007/s00132-018-3648-y] [PMID]

Belcher, A. W., et al. 2017. Incidence of complications in the post-anesthesia care unit and associated healthcare utilization in patients undergoing non-cardiac surgery requiring neuromuscular blockade 2005-2013: A single center study. Journal of Clinical Anesthesia, 43, pp. 33-8. [DOI:10.1016/j.jclinane.2017.09.005] [PMID]

Boljevic, T., et al. 2019. The quality of life of patients with surgically treated mandibular fractures and the relationship of the posttraumatic pain and trismus with the postoperative complications: A prospective study. Medicina (Kaunas), 55(4), p. 109 [DOI:10.3390/medicina55040109] [PMID] [PMCID]

Brady, J. S., et al. 2018. Association of anesthesia duration with complications after microvascular reconstruction of the head and neck. JAMA Facial Plastic Surgery, 20(3), pp. 188-95. [DOI:10.1001/jamafacial.2017.1607] [PMID] [PMCID]
Buggy, D. J. \& Crossley, A. W., 2000. Thermoregulation, mild perioperative hypothermia and postanaesthetic shivering British Journal of Anaesthesia, 84(5), pp. 615-28. [DOI:10.1093/ $\mathrm{bja} / 84.5 .615]$ [PMID]

Darvishi, A., et al., 2018. [Evaluation of the relationship between demographic information of patients' age, education and occupation on the severity of nausea and vomiting after surgery in patients undergoing general surgery with spinal anesthesia in hospitals affiliated to Shiraz University of Medical Sciences in 2018 (Persian)]. Paper presented at: The first annual student research conference of the chamber. 22 November 2018; Iran, Tehran. https://civilica.com/doc/858022/

Elsharydah, A., et al. 2020. A preoperative predictive model for prolonged post-anaesthesia care unit stay after outpatient surgeries. Journal of Perioperative Practice, 30(4), pp. 91-6. [DOI:10.1177/1750458919850377] [PMID]

Entezari-asl, M., et al. 2002. [Prevalence of post-anesthetic complications in Fatemi and Alavi Hospitals Ardabil (Persian)] Ardabil University of Medical Sciences, 2(2), pp. 12-8. http:// jarums.arums.ac.ir/article-1-559-fa.html

Finsterwald, M., et al. 2018. Spinal versus general anesthesia for lumbar spine surgery in high risk patients: Perioperative hemodynamic stability, complications and costs Journal of Clinical Anesthesia, 46, pp. 3-7. [DOI:10.1016/j.jclinane.2018.01.004] [PMID]

Fouladpour, N., et al. 2016. Perioperative complications in obstructive sleep apnea patients undergoing surgery: A review of the legal literature. Anesthesia and Analgesia, 122(1), pp. 145-51. [DOI:10.1213/ANE.0000000000000841] [PMID]

Garra, G., et al. 2013. The wong-baker pain FACES scale measures pain, not fear. Pediatric Emergency Care, 29(1), pp. 17-20. [DOI:10.1097/PEC.0b013e31827b2299] [PMID]

Kayalha, H., Roushanfekr, M. G \& Ahmadi, M., 2014. [The Comparison of ondansetron and meperidine to prevent shivering after anesthesia in patients undergoing lower limb orthopedic surgeries with general anesthesia (Persian)]. Journal of Advances in Medical \& Biomedical Research, 22(92), pp. 14-22. https:/ / emdadi.zums.ac.ir/journal/article-1-2674-en.html

Kellner, D. B., et al. 2018. Analysis of adverse outcomes in the post-anesthesia care unit based on anesthesia liability data. Journal of Clinical Anesthesia, 50, pp.48-56. [DOI:10.1016/j.jclinane.2018.06.038] [PMID]

Ma, H., et al. 2017. Warming infusion improves perioperative outcomes of elderly patients who underwent bilateral hip replacement. Medicine (Baltimore), 96(13), p. e6490. [DOI:10.1097/ MD.0000000000006490] [PMID] [PMCID]

Mendonça, F. T., et al. 2019. [Risk factors for postoperative hypothermia in the post-anesthetic care unit: A prospective prognostic pilot study (Portuguese)]. Brazilian Journal of Anesthesiology, 69(2), pp. 122-30. [DOI:10.1016/j.bjane.2018.11.002] [PMID]

Miller,R.,2015.Miller'sanesthesia.Philadelphia:Elsevier/Saunders. https:/ / books.google.com/books?id=mX2hjgEACAAJ\&dq

Misal, U. S., Joshi, S. A. \& Shaikh, M. M., 2016. Delayed recovery from anesthesia: A postgraduate educational review. Anesthesia, Essays and Researches, 10(2), pp. 164-72. [DOI:10.4103/02591162.165506] [PMID] [PMCID] 
Nasiri, A., et al. 2015. The effects of warmed intravenous fluids, combined warming (warmed intravenous fluids with humid-warm oxygen), and pethidine on the severity of shivering in general anesthesia patients in the recovery room. Iranian Journal of Nursing and Midwifery Research, 20(6), pp. 712-6. [DOI:10.4103/1735-9066.170014] [PMID] [PMCID]

Poorsheykhian, M., et al. 2012. [Incidence of post general anesthesia complications in recovery room (Persian)]. Journal of Guilan University of Medical Sciences, 21(82), pp. 8-14. https:// journal.gums.ac.ir/ / browse.php?a_id=91\&slc_lang=en\&sid $=1 \&$ printcase $=1 \&$ hbnr $=1 \& \mathrm{hmb}=1$

Poveda, V. B. \& Nascimento, A. S., 2017. The effect of intraoperative hypothermia upon blood transfusion needs and length of stay among gastrointestinal system cancer surgery. European Journal of Cancer Care, 26(6), p. e12688. [DOI:10.1111/ ecc.12688] [PMID]

Son, A., et al. 2016. Dialysis access surgery: Does anesthesia type affect maturation and complication rates? Annals of Vascular Surgery, 33, pp. 116-9. [DOI:10.1016/j.avsg.2015.12.005] [PMID]

Zhou, Y., Li, Y. \& Wang, K., 2018. Bispectral index monitoring during anesthesia promotes early postoperative recovery of cognitive function and reduces acute delirium in elderly patients with colon carcinoma: A prospective controlled study using the attention network test. Medical Science Monitor, 24 pp. 7785-93. [DOI:10.12659/MSM.910124] [PMID] [PMCID] 